\title{
Design and Construction of Urban Waste Intelligent Treatment
}

\section{System}

\author{
Xi Zhou ${ }^{1}$, Mengnan Wang ${ }^{2}$, Dexiang Deng, ${ }^{1, *}$, and $X i \mathrm{Li}^{2}$ \\ ${ }^{1}$ Professor of Chongqing University of Posts and Telecommunications , China \\ ${ }^{2}$ Chongqing University of Posts and Telecommunications , China
}

\begin{abstract}
With the rapid expansion of urban scale, urban waste disposal has become an important issue for ecological environment construction. In order to seek the coordinated development of economy and environment, we systematically intervene in urban waste intelligent treatment plans and management through design thinking and methods, and build urban waste intelligent treatment systems to achieve waste volume control, waste monitoring, classified collection, stacking and transportation, processing and Reprocessing production forms a controllable intelligent operation chain, which realizes the collaboration of human brain intelligence and artificial intelligence to improve the level of urban waste treatment and management capabilities.
\end{abstract}

Keywords:Urban Waste, Intelligent Processing, Human Brain Wisdom, Artificial Intelligence.

The advent of the $5 \mathrm{G}$ information era and the widespread use of artificial intelligence AI and remote sensing technologies have promoted the construction of smart cities to a new level, and also provided technical support for the intelligent treatment of urban waste. However, the construction of smart cities has not touched the waste too much. Handle this link intelligently. Although the efficiency of urban waste treatment has been significantly improved with the development of science and technology, the wisdom of urban waste treatment is still far behind other smart areas in the city. The intelligent treatment of urban waste has not yet formed a complete system, and it is difficult to satisfy the social economy. Development, the construction of the ecological environment and the improvement of people's living standards. Scientific, standardized, efficient, and sustainable waste treatment are all important evaluation indicators for urban operation and development. Therefore, the use of design thinking to study the design of urban waste smart treatment system has important practical significance for the construction of smart cities and the industrialization of waste treatment.

\section{Continuous cr acking of ur ban waste treatment problems}

With the development of our country's industrialization and the expansion of urban scale, urban waste has doubled. According to statistics, "China produces hundreds of millions of tons of garbage each year, and the annual output of garbage per capita in cities is 440 kilograms. There are 8 billion tons of garbage piled in 600 cities across the country." [1] Since our country has not implemented all-round garbage classification, urban domestic garbage is common. Mixed collection methods

*Corresponding author: 2377230006@qq.com 
are adopted. Different types of garbage are collected together, which increases thedifficulty and cost of subsequent garbage treatment. Part of the recyclable garbage is treated as hazardous garbage, and the recyclable garbage is rare. ${ }^{[2]}$ Urban waste disposal has become a difficult problem facing my country's economic development and environmental and ecological civilization construction. Our country's urban waste treatment has undergone the process of composting, landfilling and incineration, and waste incineration power generation has become a new form of waste treatment and utilization in our country. Compared with developed countries, our country has a late start in waste treatment, partial implementation of waste sorting, waste incineration power generation has just started, and a long way to go for urban waste treatment.

The West has also experienced the garbage dilemma and the continuous process of solving the problem under the industrial civilization. Germany is its representative. "In 1972, the Capital's'Waste Management Law' was passed and the treatment of urban garbage was initiated. The Circulation and Waste Management Law has promoted the recycling of garbage," ${ }^{[3]}$ Now $60 \%$ of German urban waste is recycled, and the recycling rate of waste is the highest in the world. Sweden is also effective in solving problems in waste recycling. Its waste treatment methods are divided into four levels. They first consider recycling. If recycling is difficult, they choose to use biotechnology. If biotechnology cannot be processed, they will be incinerated, and those that cannot be incinerated will be landfilled. In the end, the proportion of landfill disposal is very low. In comparison, the treatment of the urban waste system in Florence is extremely environmentally friendly and interesting. It has a successful recycling and food waste composting program. It has almost unlimited cheap and ubiquitous waste transportation options for recyclable waste. Recycling and transportation, and it has a vibrant slow food and organic restaurant community consisting of a food waste composting program, and a strong sustainable agriculture and biodynamic wine community to digest food waste compost.

Japan is the representative of environmental protection and waste treatment in Asian countries, and its success lies in the education of environmental protection to citizens. Since 1997, Japan has issued detailed rules on waste classification, requiring every citizen from children to elderly people to actively learn waste classification. This has promoted the overall awareness and awareness of waste classification. Due to the extremely limited land resources in Japan, there are strict regulations on the collection date and disposal time of waste.

On the whole, the world is paying more and more attention to the comprehensive utilization and recycling of garbage, and it continues to solve the problem of urban waste treatment. The efficiency of waste treatment is also improving. The new technology of waste treatment is continuously used, but the requirements of the global sustainable development concept are still There is a big gap, and there is still a long way to go to match the smart earth and smart city construction.

\section{Design of $U$ rban $W$ aste I ntelligent Treatment System}

"Our country has promulgated the Urban Domestic Garbage Treatment and Pollution Prevention Technology Policy", in which the treatment of domestic waste should be aimed at ensuring public sanitation and human health, preventing environmental pollution, and following the principle ofreduction, resource utilization and harmlessness' The United Nations Commission on Environment and Development put forward the concept of sustainable development in 1987, and its purpose is to meet the current needs of people under the premise of protecting the environment, without compromising the production and development of future needs. Urban development needs the guidance of sustainable theory, and its basic requirement is that the environmental impact is less than the environmental carrying capacity.

As an important part of the urban ecological system, the urban waste disposal system is inseparable from the natural resource environment, economic development status, and social activities. In order to meet their own service needs, human beings draw resources from the natural environment for material production and promote economic development. The purpose is to create better production and living conditions. However, in this process, waste is inevitably produced. A sustainable urban waste smart disposal system is needed to help waste return to 
the natural environment in different forms to achieve harmony between man and nature. For this reason, we must first solve how to avoid generating less waste from the source, secondly solve the rational stacking and rapid removal of waste, thirdly achieve the harmless processing and reproduction of waste, and finally waste monitoring and supervision. It is the four subsystems that make up the urban waste treatment system. These four subsystems cooperate with the design and application of modern information and communication technology and artificial intelligence to realize intelligent independent operation and linked collaborative operation. This is our definition of the urban waste intelligent treatment system. This system requires us to use design thinking for architecture design. ${ }^{[4]}$

\subsection{Waste limit led by human wisdom}

Design and construct a waste control mechanism involving the government, society, enterprises and individuals to limit waste production from the source. ${ }^{[5]}$ This requires an integrated design from the macro and micro aspects of system, law, education, management, etc. To unify the social awareness and behavior of waste control; the total amount of waste production limit and quantity control design can be carried out, and everyone is designed to comply with their waste. Classification related rules, design to encourage the scientific and technological application in the waste field to reduce the output mechanism of waste and reward units and individuals that produce less waste in production and life, etc.

The amount of production waste berestrictedand the paid treatment mechanism was designed, and the amount of waste generated is controlled through economic levers such as paid treatment and paid transfer of weight indicators. Strengthen the cultivation of social ethics for the control of domestic waste, so that people can control the production of domestic waste in actual life activities. ${ }^{[6]}$ To reduce waste generation through social behavior design, one of Florence's ways to reduce the number of plastic bottles in the waste stream is to encourage people to carry reusable plastic bottles during the trip, and install water dispensers with convenient water supply in the city to provide people with free replenishment drinking water.
In this system, more human wisdom plays a role. Of course, the use of modern information technology and big data produced by cloud computing can provide smarter design support for the use of human wisdom to limit the total amount and quantity of waste. ${ }^{[7]}$

\subsection{Design of intelligent waste s orting, s tacking and removal system led by artificial intelligence}

Waste classification is an effective prerequisite for reducing the amount of processing, the most important link in the front end of the urban waste intelligent processing system, and the forerunner of the entire system. Reasonable waste classification can improve the efficiency of subsequent waste treatment and speed up different waste distribution and treatment methods. The ultimate purpose of waste classification is to realize the recycling and reuse of resources, thereby building a conservation-oriented and environment-friendly society. To this end, the government, society, and the public should all attach importance to waste classification. The behavior and attitude of the people are the key to waste classification.

\subsubsection{Comprehensively promote the classification of domestic waste}

Strengthen the cultivation of domestic waste classification awareness and classification behavior, so that domestic waste can be stored or stacked in classification. In July 2019, Shanghai began to implement the Compulsory Classification of Domestic Waste in November 2019, the Regulations of Beijing Municipality on the Management of Domestic Waste revised and approved by the Standing Committee of the Beijing Municipal People's Congress were also implemented on May 1 this year. Many cities are also advocating the classification of domestic waste or preparing for mandatory classification of domestic waste. This series of measures shows that the national level attaches great importance to the value of domestic waste classification and strengthens the role of everyone in the classification of domestic waste. The publicity and guidance of garbage classification followed closely. The Internet, TV programs, and major media have continuously promoted garbage classification and its basic knowledge, which has spread to citizens and 
children. The awareness of social garbage classification and behavior continues to increase. However, compared with most provinces and cities in my country, the relevant management regulations and implementation plans for waste classification have not yet been finalized, and the nationwide waste classification action should be accelerated to implement waste sorting and storage. ${ }^{\left[{ }^{8]}\right.}$

\subsubsection{Promote the classification of production waste}

Implement a classification code system for production materials, compulsorily implement various material labels on products and packaging and product overall category labels, production waste is classified according to material identification codes, and waste products after use are according to overall categories identification code classification or classification according to the material identification code for subsequent better scanning and classification processing.

\subsubsection{Continue to promote intelligent waste classification}

Based on the social awareness and behavioral habits of producing domestic garbage classification, promote the R\&D and production of facilities and equipment for smart garbage classification at the national level, promote the process of smart garbage classification, and make the first link after garbage generation Realize smart classification and provide basic guarantee for subsequent garbage classification and treatment.

\subsubsection{Fixed-point closed storage and closed collection and transportation of waste}

Three-level garbage dumping points for residential wastes, communities, and streets, two-level garbage dumping points for responsible units and streets for production waste and public waste, and a multi-level airtight for urban garbage Clearance system. Design and build an intelligent tracking and monitoring system for the sealed storage and transportation of urban garbage, and use Internet technology and GPS to track and monitor the sealing state and process of garbage storage and transportation in real time to avoid pollution of the environment and air causedby garbage storage and transportation.

\subsection{Smart and harmless "processing and reproduction" system for urban waste}

Through the design of intelligent waste sorting facilities, the recyclable waste of production and domestic waste is converted into direct monetary benefits through the waste generator as much as possible. Not only can the waste recycling rate be used for recycling, but also harmful waste and moisture can be minimized. The amount of space occupied, removal and disposal of garbage.

Build a smart waste treatment station to intelligently classify and treat the hazardous waste and environmentally polluted waste that can be treated with the recycling value of waste. For example, composting technology separates organic waste from inorganic waste, and organic waste generates organic fertilizer for reuse, inorganic Waste is converted into energy for power generation and heating through incineration. If the rest of the waste cannot be treated with the above technology, then the waste is treated with non-permeable landfill technology. ${ }^{[9]}$ The specific process is as shown in (see Fig.1).

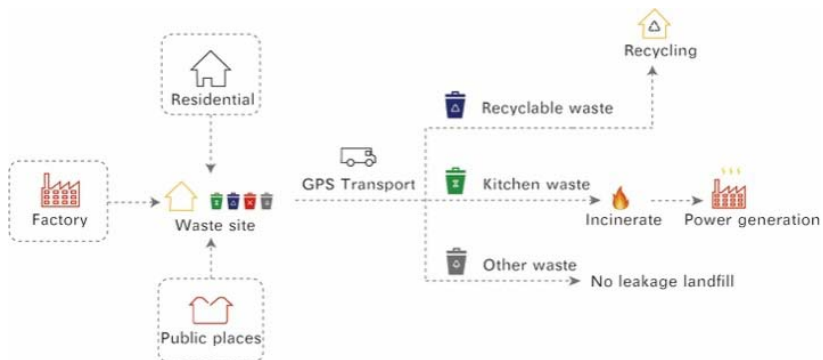

Fig.1.Flow chart of garbage disposal (picture source: drawn by the author).

Regarding landfill disposal, we must be cautious and try to replace it with incineration power generation, composting waste treatment technology or new harmless treatment technology to prevent landfill leachate from polluting soil and groundwater resources.

\subsection{Intelligent waste monitoring and supervision led by artificial intelligence}

\subsubsection{Urban garbage remote sensing image detection system}


Based on the construction of the city's image and the environmental ecology, the phenomenon of garbage siege and the problem of garbage pollution to the environment have been eliminated, and remote sensing image technology has been introduced to continuously detect and monitor the surrounding environment of the city. Especially in the urban villages and the suburban villages in the suburban area, it is prone to factors such as unclear waste management responsibility, high collection and transportation costs, etc.It is very easy to form long-term unmanaged waste storage sites, plus long-term open-air stacking and mixed stacking. As the air, water and soil are seriously polluted, the detection and monitoring and management of garbage in these areas should be strengthened. ${ }^{[10]}$

Remote sensing detection, as a part of the urban garbage smart processing system, is mainly used to search for unmanaged or poorly managed garbage dump sites, identify garbage dump patterns, and monitor urban environmental garbage in real time. ${ }^{[11]}$ Through the analysis of the color, texture, light color, geographic location, and stacking morphology of the detected high-resolution and multi-spectral images, for comprehensive and effective garbage supervision. ${ }^{[12]}$

\subsubsection{Urban waste ecological monitoring system}

Waste is an important source of environmental pollution. For the design of intelligent waste treatmentsystem, the urban waste ecological monitoring system is indispensable. The air data and water and soil quality data of the garbage dump area are measured through the systematic garbage ecological monitoring system to evaluate our garbage disposal level. ${ }^{[13]}$ The design of the monitoring system should set up various sensors and monitors with smart recognition from the garbage collection bins, garbage transfer stations, and garbage disposal stations, and quickly transmit data to the corresponding garbage management platform through wireless communication technology. The platform immediately responded and conveyed its specific information to the nearby sanitation workers for timely processing (see Fig.2).

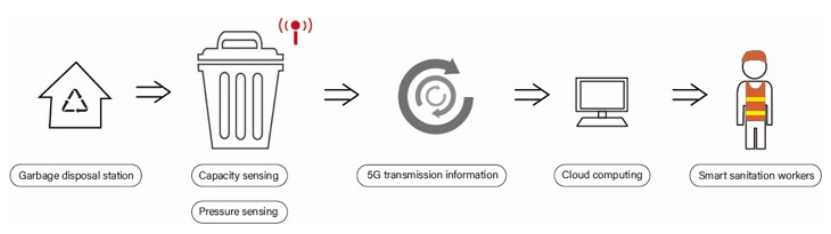

Fig.2.Intelligent waste disposal (picture source: drawn by the author).

\section{Peroration}

The new generation of information technology has very important application value in the intelligent treatment of urban waste. The smart waste treatment system with design thinking has transformed waste treatment from low-energy and low-efficiency traditional passive treatment methods into sustainable recycling production methods. The efficiency of waste treatment is improved, and waste monitoring, collection, classification, cleaning and transportation, treatment, and reprocessing are formed into a controllable intelligent operation chain, which can effectively solve the coordination problem of urban resources, environment and economic development. The design of the urban waste smart disposal system is connected with economic, social, cultural, and ecological aspects. It needs to make full use of modern artificial intelligence technology to improve processing efficiency. At the same time, it also requires the participation of people's wisdom and behavior to achieve the synergy of artificial intelligence and human brain wisdom.

\section{References}

1. T. S. Shen, Design of product service system for sustainable municipal solid waste system. Doctor, Jiangnan University(2013)

2. Y. Y. Zhan, Analysis of the status quo of garbage classification and recycling in my country. Business situation,33(2018)

3. Z. Y. Zhang, Research on Environmental Management of Municipal Solid Waste Collection and Treatment. Resource conservation and environmental protection, 135(2020)

4. W. S. Liu, Ndustrial treatment of municipal solid waste from the perspective of system design. Packing Engineering,40(10):179-185(2019)

5. E. MOFID -NAKHAEE, F. Barzinpour, M. S. 
PISHVAEE, A sustainable municipal solid waste system design considering public awareness and education: a case study. Waste Management \& Research,38(6): 23-24 (2020)

6. Y. Z. Wang, Research on the Mechanism of Municipal Solid Waste Treatment. Environmental monitoring and early warning,12 (2020)

7. T. Li, Research on the construction of a smart city waste sorting and processing platform and standard system. Standard Science,9(2019)

8. F. Y. Zhu, Thoughts on the Disposal Methods of Domestic Garbage in Urban Environmental Sanitation Planning. Resource conservation and environmental protection,133(2020)

9. H. Z. Liu, J. W. Yang, Feasibility analysis of waste incineration power generation in small and medium cities. Technology Communication,11(2016)

10. H. Fan, L. Huang, Remote Sensing and Geographic Information System for the Inspection, Monitoring and Management of Domestic Waste Landfill Sites.Jiangxi Chemical Industry, 04(2004)

11. X. T. Zhang, Y. J. Xiang, Talking about the resource advantages of waste-to-energy. Power grid and clean energy,06(2016)

12. Z. L. Hu, Suggestions for the development of domestic garbage industry in my country.Inner Mongolia Technology and Economy,4(2001)

13. C. F. Hu, The Status Quo of the Classification and Treatment of Urban Domestic Waste in my country and the Countermeasures. Environment and development,32(202) 